\title{
Effects of Thyroid Hormone on Cardiac Size and Myosin Content of the Heterotopically Transplanted Rat Heart
}

\author{
Irwin Klein and Chull Hong \\ Departments of Medicine and Surgery, University of Pittsburgh School of Medicine and the Veterans \\ Administration Hospital, Pittsburgh, Pennsylvania 15261
}

\begin{abstract}
Infrarenal heterotopic cardiac isografts maintain structural and functional integrity. We have used this transplantation model to further explore the mechanisms of thyroid hormone-induced cardiac hypertrophy. Thyroid hormone administration, 1-thyroxine $\left(T_{4}\right) 10 \mu \mathrm{g} /$ animal per $d$, led to a significant $30 \%$ increase in total heart weight and a $\mathbf{4 0 \%}$ increase in the myosin content of the in situ heart when compared with control. In contrast, $T_{4}$ treatment was without effect on the heart weight, protein content, rate of protein synthesis, or calculated myosin content of the heterotopic, nonworking heart. Heterotopic hearts demonstrated a significant decrease in the percentage of the $V_{1}$ myosin isoenzyme from $95 \%$ to $61 \%$. This shift occurred in euthyroid animals but was prevented by $T_{4}$ treatment. These results suggest that thyroxine-induced cardiac hypertrophy is mediated indirectly via changes in cardiac work. Myosin isoenzyme expression can be altered by changes in work load but is still responsive to increased levels of thyroid hormone.
\end{abstract}

\section{Introduction}

Both naturally occurring and experimental hyperthyroidism are associated with predictable changes on the heart and cardiovascular system (1-3). Previous studies have shown that administration of excess thyroid hormone leads to increased synthesis of RNA, increased protein synthesis, and the development of cardiac hypertrophy $(4,5)$. These changes in the myocardial protein synthesis occur in association with an increased heart rate, cardiac output, increased myocardial contractility, and the development of cardiac hypertrophy $(1,3,6)$. Thus the hyperthyroid heart performs increased work, a stress similar to that shown by others to produce cardiac hypertrophy $(6,7)$.

Thyroid hormone exerts its biologic activity by binding to discrete nuclear receptors, with the subsequent alteration in the rate of RNA transcription leading to the synthesis of specific proteins (8). One of these proteins is the membrane enzyme $\mathrm{Na}^{+} / \mathrm{K}^{+}$ATPase which is present in the plasma membrane of the myocardium (9). Previous studies have suggested that increases in cardiac protein synthesis and cardiac contractility can be a result of a direct effect of thyroid hormone on the heart $(10,11)$.

To further investigate the mechanism of thyroid hormonemediated cardiac hypertrophy, we have employed a model in

Address all correspondence to Dr. Klein, Division of Endocrinology, North Shore University Hospital, Manhasset, NY 11030.

Received for publication 18 November 1985.

J. Clin. Invest.

(c) The American Society for Clinical Investigation, Inc.

0021-9738/86/05/1694/05 \$1.00

Volume 77, May 1986, 1694-1698 which a heterotopically transplanted heart coexists with the recipient's in situ working heart. We compared the effects of thyroid hormone on total heart weight, total heart protein, protein synthesis, myosin content, and the expression of myosin isoenzymes in both the in situ as well as the heterotopically transplanted heart. The ability to maintain nonworking vascularly perfused transplanted heart tissue for prolonged periods of time in vivo (12) permits the dissociation of the direct effects of thyroid hormone on the myocardium from those mediated indirectly by increases in cardiac work.

\section{Methods}

Thyroxine $\left(\mathrm{T}_{4}\right),{ }^{1}$ histidine, and ATP (disodium salt, vanadium free) were purchased from Sigma Chemical Co., St. Louis, MO. Sodium desoxycholate, EDTA, trichloroacetic acid (TCA), and $d$-mannitol were from Fisher Scientific Co., Pittsburgh, PA. Acrylamide, bis-acrylamide, Coomassie Blue (R-250), EDTA, and Tris buffer for gel electrophoresis were obtained from Bio-Rad Laboratories, Richmond, CA. $\left[{ }^{3} \mathrm{H}\right] l y s i n e(90 \mathrm{Ci} /$ $\mathrm{mM}$ ) was purchased from New England Nuclear, Boston, MA. Inbred male Lewis rats weighing between 145 and $170 \mathrm{~g}$ were obtained from Charles River Breeding Laboratories, Inc., Wilmington, MA.

Infrarenal heterotopic cardiac isograft was performed by the technique of Ono and Lindsey (12). This is accomplished by anastamosis of the end of the donor heart aorta to the side of the recipient abdominal aorta. Next, the donor pulmonary artery is connected to the inferior vena cava of the recipient animal to return myocardial blood flow. The left ventricle (LV) is unloaded and does no external work. The animals were divided into two groups, and $24 \mathrm{~h}$ after completion of the surgery, group I received daily subcutaneous injections with $0.1 \mathrm{ml}$ of sterile phosphate-buffered saline (PBS) (50 mM Na $2 \mathrm{HPO}_{4}, \mathrm{pH} \mathrm{7.4)} \mathrm{and} \mathrm{group} \mathrm{II} \mathrm{received} \mathrm{subcu-}$ taneous injections of $10 \mu \mathrm{g} \mathrm{T} \mathrm{T}_{4}$ in $0.1 \mathrm{ml}$ PBS. Animals were weighed daily and after $14 \mathrm{~d}$ of treatment both in situ and grafted heart rates were determined in four animals from each group by appropriate electrocardiogram lead placement. The animals were sacrificed and aliquots of blood from each rat were taken for determination of serum $T_{4}$ and triiodothyronine $\left(T_{3}\right)$ levels by radioimmunoassay. Whole hearts were removed, rinsed in cold PBS, blot dried, and weighed after removal of the atria and remaining great vessels and connective tissue. LVs, including the intraventricular septum, were isolated and also weighed. Precisely weighed pieces were taken from each ventricle for myosin ATPase assay, myosin isoenzyme analysis, and total protein determination.

Myosin extraction and myosin ATPase assay. A 100-mg portion of LV was homogenized in $7 \mathrm{ml}$ of a buffer containing $40 \mathrm{mM} \mathrm{NaCl}$ and $3 \mathrm{mM} \mathrm{Na}_{2} \mathrm{HPO}_{4}$ at pH 7.0 in a Potter-Elvehjem homogenizer (Kontes Co., Vineland, NJ) and centrifuged at $800 \mathrm{~g}$ for $10 \mathrm{~min}$. The pellet was washed once in an equal volume of the same buffer, and then resuspended in $3 \mathrm{ml}$ of a myosin extraction buffer containing $100 \mathrm{mM} \mathrm{Na}_{4} \mathrm{P}_{2} \mathrm{O}_{7}, 5$ mM EGTA, $5 \mathrm{mM}$ dithiothreitol, $5 \mathrm{mM} \mathrm{ATP}, 5 \mathrm{mM} \mathrm{MgCl}$, and $5 \mu \mathrm{g} /$ $\mathrm{ml}$ leupeptin at $\mathrm{pH}$ 8.6. The homogenate was extracted at $3^{\circ} \mathrm{C}$ for $1 \mathrm{~h}$ and then centrifuged at $100,000 \mathrm{~g}$ for $1 \mathrm{~h}$. After removing an aliquot for isoenzyme analysis, the supernatant was dialyzed overnight at $3^{\circ} \mathrm{C}$ against

1. Abbreviations used in this paper: bpm, beats per minute; $\mathrm{LV}(\mathrm{s})$, left ventricle(s); $P$, protein; $\mathrm{Pi}$, inorganic phosphate; $\mathrm{T}_{3}$, triiodothyronine; $T_{4}$, 1-thyronine. 
a buffer containing $0.5 \mathrm{M} \mathrm{KCl}, 0.5 \mathrm{mM}$ cysteine ( $\mathrm{pH} 7.0$ ) as previously described (13).

Myosin ATPase activity was assayed in $1 \mathrm{ml}$ of an incubation medium containing $0.5 \mathrm{M} \mathrm{KCl}, 5 \mathrm{mM} \mathrm{NaN}_{3}, 10 \mathrm{mM} \mathrm{CaCl}_{2}, 1 \mathrm{mM} \mathrm{ATP}, 100$ $\mathrm{mM}$ glycine at $\mathrm{pH} 9.1$, and $50-100 \mu \mathrm{g}$ of extract protein. The reaction was performed at $25^{\circ} \mathrm{C}$ for $5 \mathrm{~min}$ and terminated by adding an equal volume of $10 \% \mathrm{TCA}(\mathrm{wt} / \mathrm{vol})$. After centrifugation at $1,000 \mathrm{~g}$ for $10 \mathrm{~min}$, aliquots of the supernatant were assayed for liberated inorganic phosphate (Pi) (13). Enzyme assays were performed in duplicate with the final change of dialysis buffer used as the reaction blank. Under standard conditions the assay was linear for up to $20 \mathrm{~min}$ and $<10 \%$ of the substrate was hydrolyzed during the 5-min incubation.

Protein determination. To quantitate the total protein content of each rat heart, a portion of left ventricular myocardium was removed and precisely weighed. The tissue was homogenized in a fixed volume of $\mathrm{NaOH}(1 \mathrm{~N})$ and protein was determined according to the method of Lowry et al. (14).

Total protein synthesis was measured by the incorporation of $\left[{ }^{3} \mathrm{H}\right]$ lysine into TCA precipitable protein. Exactly $24 \mathrm{~h}$ before sacrifice each animal was injected subcutaneously with $5 \mu \mathrm{Ci}$ of $\left[{ }^{3} \mathrm{H}\right]$ lysine in 0.1 $\mathrm{ml}$ of PBS. At the time of sacrifice an aliquot of the total protein homogenate was made to $10 \%(\mathrm{wt} / \mathrm{vol})$ with TCA and centrifuged at 1,000 $g$ for $10 \mathrm{~min}$. The precipitate was washed once in $10 \%$ TCA, recentrifuged, and solubilized in $1 \mathrm{ml}$ of $1 \mathrm{NaOH}$, and the radioactivity determined in a Tri-Carb model $300 \mathrm{C}$ scintillation counter (Packard Instrument Co., Downers Grove, IL).

Nondenaturing gel electrophoresis. Nondenaturing polyacrylamide electrophoresis was performed on myosin extracts according to the methods of Hoh et al. (15). Electrophoresis was performed using polyacrylamide at a final concentration of $4 \%(\mathrm{wt} / \mathrm{vol})$ with $0.12 \%(\mathrm{wt} / \mathrm{vol})$ bis-acrylamide as previously described (13). The gels were developed for $18 \mathrm{~h}$ at a constant voltage of $100 \mathrm{~V}$ in a recirculated buffer containing $\mathrm{Na}_{4} \mathrm{P}_{2} \mathrm{O}_{7} 20 \mathrm{mM}$, glycerol $10 \%$ (vol/vol) at $\mathrm{pH} 8.8$.

The gels were fixed with TCA $10 \%(\mathrm{wt} / \mathrm{vol})$, methanol $50 \%$ (vol/vol) for $4 \mathrm{~h}$ and then stained for $3 \mathrm{~h}$ with Coomassie Blue (R-250) $0.03 \%$ (wt/vol) in isopropanol 25\% (wt/vol), and acetic acid $10 \%$ (vol/vol). The gels were destained with acetic acid $7 \%(\mathrm{vol} / \mathrm{vol})$ and methanol $20 \%$ (vol/vol). Individual isoenzyme band heights were quantitated by densiometric scanning at a wavelength of $550 \mathrm{nM}$ with a model $260 \mathrm{spec}-$ trophotometer (Gilford Instrument Laboratories, Inc., Oberlin, $\mathrm{OH}$ ) equipped with a linear gel scanner. Equal amounts of extract protein are routinely applied to each gel.

Myosin quantitation. Myocardial myosin content was determined based upon the measured specific activity of myosin ATPase, the quantity of total protein in the myosin extracts, and the previously determined specific activities for homogeneously purified myosin of known isoenzyme content $(13,16)$. This was performed according to the equation: myosin content $=($ myosin ATPase specific activity $[\mu \mathrm{M} \mathrm{Pi} / \mathrm{mg} \mathrm{P}] \times$ total extract protein [mg P])/(calculated myosin ATPase specific activity $\left[V_{1}, V_{2}, V_{3}\right.$, $\mu \mathrm{M} \mathrm{Pi} / \mathrm{mg} \mathrm{P}]$ ), where the denominator is calculated using the measured isoenzyme distribution in the formula $=\left(\% \mathrm{~V}_{1} \times 12.8 \mu \mathrm{M} \mathrm{Pi} / \mathrm{mg} \mathrm{P}\right)$ $+\left(\% \mathrm{~V}_{2} \times 6.0 \mu \mathrm{M} \mathrm{Pi} / \mathrm{mg} \mathrm{P}\right)+\left(\% \mathrm{~V}_{3} \times 1.2 \mu \mathrm{M} \mathrm{Pi} / \mathrm{mg} \mathrm{P}\right)$. The percentage of myosin isoenzymes is derived from the scan of nondenaturing gels.
The specific activities for isomyosin $V_{1}$ and $V_{3}$ were measured from homogeneous rat ventricular myosin samples purified in our laboratory $(13,17)$ and for $V_{2}$ from the data of Dillmann $(16)$.

Statistical analyses were performed using an analysis of variance and the Kramer adjustment to compare multiple treatment groups of different sample sizes (18). Data are expressed as the mean \pm SEM.

\section{Results}

Maintenance of functional integrity and structure of the syngeneic heterotopic transplanted heart for periods of up to 6 mo has been previously documented $(12,19)$. In our laboratory, histologic evidence of structural integrity includes normal fiber structure and striations, maintenance of cell-cell contact, and lack of cellular necrosis at the light microscopic level. Functional integrity was demonstrated by the maintenance of a spontaneous sinus heart rate $>200$ beats per minute (bpm) and the maintenance of a constant duration ventricular complex (rate corrected) measured on the electrocardiogram (19).

In the Lewis strain of rats, the adult heart weight (both ventricles after removal of atria and great vessels)/body weight ratio was determined to be $2.60 \pm 0.13 \times 10^{-3}$. Thus, at the time of transplantation, the calculated heart weights (based on the animals' body weights) for both donor and recipient hearts were $376 \pm 10 \mathrm{mg}$. In control animals the in situ heart increased in weight by $54 \%$ to $582 \pm 18 \mathrm{mg}$ over a 2 -wk period, while the nonworking, heterotopic heart decreased in size by $23 \%$ to $293 \pm 8$ mg (Table I).

At the time of sacrifice, measurements of total heart protein, total left ventricular protein, and total myosin content were all significantly decreased in the transplanted heart when compared with the in situ heart. Thus, the heterotopic heart demonstrated a significant degree of atrophy; this involved all components of cardiac size and protein content measured. Direct measurements of heart rate just before sacrifice showed a significant decline in the spontaneous rate of the denervated heterotopic heart when compared with the working heart (Table II). The measurement of myosin ATPase specific activity was significantly lower in the transplanted heart. This fall in enzyme activity was associated with a shift in the myosin isoenzyme distribution from $V_{1}$ to an increase in $V_{2}$ and $V_{3}$ as demonstrated in Table $I$ and Fig. 1.

Effects of L-thyroxine treatment. Serum levels of $\mathrm{T}_{4}$ (micrograms per deciliter) measured at the time of sacrifice were $6.5 \pm 0.3$ in control and $18.7 \pm 0.5$ in $\mathrm{T}_{4}$-treated animals. $\mathrm{T}_{3}$ levels (nanograms per milliliter) were 0.62 and 1.34 , respectively. There was no significant difference in the body weight between the two groups of animals after $14 \mathrm{~d}$ of treatment. Thyroid hormone administration was associated with the development of cardiac

Table I. Effect of Cardiac Location and Thyroid Hormone Treatment on Heart Size and Myosin Content

\begin{tabular}{|c|c|c|c|c|c|c|c|c|c|}
\hline Group & Heart location & Treatment & Body weight & Heart weight & $\begin{array}{l}\text { Total heart } \\
\text { protein }\end{array}$ & Total LV protein & $\begin{array}{l}\text { Myosin } \\
\text { ATPase }\end{array}$ & $v_{1}$ & $\begin{array}{l}\text { Total myosin } \\
\text { content }\end{array}$ \\
\hline & & & $g$ & $m g$ & $m g$ & $m g$ & $\begin{array}{l}\mu M P i / m g P \\
\text { per } 5 \text { min }\end{array}$ & $\%$ & $m g$ \\
\hline IA & In situ $n=8$ & PBS & $232 \pm 4$ & $582 \pm 18 \ddagger$ & $127 \pm 8 \ddagger$ & $82 \pm 5 \ddagger$ & $5.81 \pm 0.16$ & $95 \pm 2$ & $15.6 \pm 1.9 \ddagger$ \\
\hline IIA & In situ $n=7$ & $\mathbf{T}_{4}$ & $238 \pm 3$ & $745 \pm 23^{*}$ & $182 \pm 4^{*}$ & $119 \pm 2 *$ & $6.06 \pm 0.10$ & $98 \pm 1$ & $21.8 \pm 1.4^{*}$ \\
\hline IB & Heterotopic $n=8$ & PBS & & $293 \pm 8$ & $62 \pm 4$ & $45 \pm 2$ & $4.43 \pm 0.13 \S$ & $61 \pm 4 \S$ & $6.8 \pm 0.4$ \\
\hline IIB & Heterotopic $n=7$ & $T_{4}$ & & $306 \pm 12$ & $73 \pm 5$ & $49 \pm 3$ & $5.48 \pm 0.11$ & $97 \pm 2$ & $7.3 \pm 0.5$ \\
\hline
\end{tabular}

Data are mean \pm SEM. * Greater than IA, IB, IIB, $P<0.01$. $\ddagger$ Greater than IB, IIB, $P<0.01 . \quad \S$ Less than IA, IIA, IIB, $P<0.01$. 
Table II. Effect of Thyroid Hormone Treatment on Heart Rate and $\left[{ }^{3} \mathrm{H}\right]$ Lysine Incorporation

\begin{tabular}{|c|c|c|c|c|}
\hline Group & Heart location & Treatment & Heart rate & {$\left[{ }^{3} \mathrm{H}\right]$ Lysine incorporation } \\
\hline & & & $b p m$ & cpm/heart \\
\hline IA & $\begin{array}{l}\text { In situ } \\
\quad n=4\end{array}$ & PBS & $398 \pm 25 \S$ & $2142 \pm 59 \ddagger$ \\
\hline IIA & $\begin{array}{l}\text { In situ } \\
\quad n=4\end{array}$ & $T_{4}$ & $465 \pm 15^{*}$ & $2847 \pm 64^{*}$ \\
\hline IB & $\begin{array}{c}\text { Heterotopic } \\
n=4\end{array}$ & PBS & $248 \pm 19$ & $1165 \pm 47$ \\
\hline IIB & $\begin{array}{c}\text { Heterotopic } \\
\quad n=4\end{array}$ & $T_{4}$ & $368 \pm 15 \S$ & $1081 \pm 23$ \\
\hline
\end{tabular}

Data are mean \pm SEM.

* = Greater than IA, $P<0.05$, and IB, IIB, $P<0.01$.

$\ddagger=$ Greater than IB, IIB, $P<0.05$.

$\S=$ Greater than IB, $P<0.01$.

hypertrophy in the in situ working heart as recorded in Table I and Fig. 2. Total heart weight, total heart protein, LV weight, and $L V$ protein were significantly increased in response to $T_{4}$ treatment as compared with control. In contrast, $T_{4}$ treatment was without effect on any of the parameters of cardiac size or cardiac protein content of the heterotopic nonworking heart.

Thyroid hormone administration was associated with an increase in heart rate from $398 \pm 25$ to $465 \pm 15 \mathrm{bpm}$ when in situ hearts were compared. It is of note that the measured spontaneous heart rate of the denervated heterotopic heart in the $\mathrm{T}_{4^{-}}$ treated animals was significantly greater than its counterpart in control animals, and not significantly less than that recorded for the control innervated in situ heart.

Measurements of myosin ATPase in extracts of left ventricular myocardium were not significantly different in either group of in situ hearts. However, there was a significant fall in the specific activity for the myosin ATPase activity measured in the control heterotopic heart which was not observed in the thyroid hormone-treated heterotopic myocardium (Table I). To assess

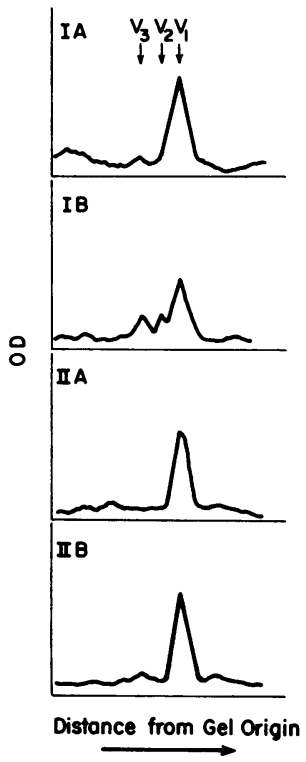

Figure 1. Comparison of the myosin isoenzyme distribution from ventricular extracts of the four experimental groups. Myosin isoenzymes were separated by nondenaturing gel electrophoresis and quantitated by densiometric scanning at $500 \mathrm{nM}$. IA, in situ control; IB, heterotopic control; IIA, in situ $\mathrm{T}_{4}$-treated; IIB, heterotopic $\mathrm{T}_{4}$-treated. The relative mobilities for standard myosin isoforms are indicated by arrows above.

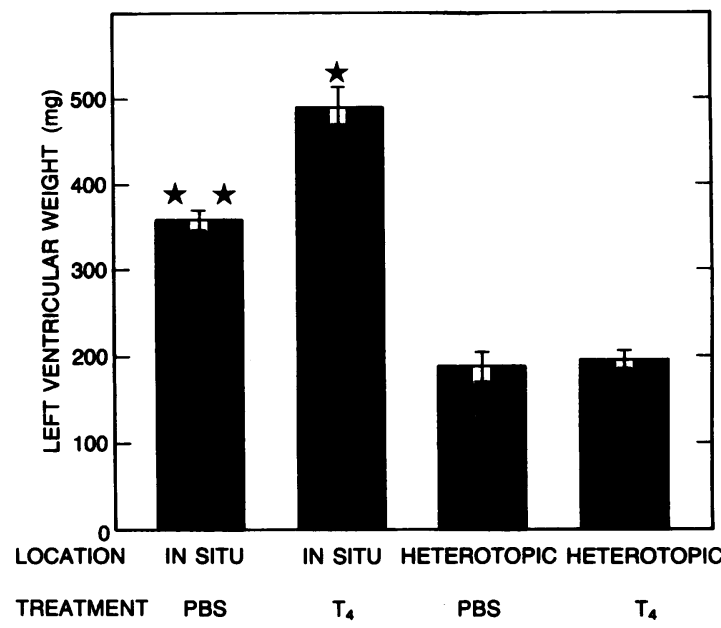

Figure 2. Effect of cardiac location and thyroid hormone treatment on left ventricular weight. Treatment with $T_{4}$ was at $10 \mu \mathrm{g} /$ animal per $\mathrm{d}$. $\star$, Significantly greater than all other groups. $\star \star$, Significantly greater than either of the heterotopically transplanted hearts.

the possible mechanisms for these changes, myosin isoenzyme distributions were examined in the four groups of hearts. When the percentage of $V_{1}$ isoenzyme in control in situ hearts was compared with control heterotopic hearts there was a significant decrease as noted above. $T_{4}$ treatment restored the myosin isoenzyme distribution to a $V_{1}$ predominence in the heterotopic transplanted heart (Fig. 1).

Based upon measurements of $(a)$ myosin ATPase specific activity, $(b)$ extract protein, and $(c)$ myosin isoenzyme distribution it was possible to calculate the total heart and left ventricular myosin contents. Table I lists the myosin content for the four groups of animals. The myosin content of the $\mathrm{T}_{4}$-treated in situ hearts was greater than the in situ control, which in turn was significantly greater than the content of either group of heterotopic hearts. There was no difference in the myosin content between the two groups of transplanted hearts. These changes in myosin content were similar to the differences recorded for total heart and LV protein.

Measurements of total protein synthesis as reflected by the incorporation of $\left[{ }^{3} \mathrm{H}\right]$ lysine into TCA precipitable protein are listed in Table II. The data are expressed as counts per minute per total heart. Transplanted hearts in control animals had significantly lower $\left[{ }^{3} \mathrm{H}\right]$ lysine incorporation when compared with the in situ heart. This rate of incorporation did not increase in the heterotopic myocardium in response to $T_{4}$ treatment, in contrast to that observed for the in situ working heart.

\section{Discussion}

Thyroid hormone could promote the development of cardiac hypertrophy either by a direct effect on the rate of myocardial protein synthesis or indirectly through changes in cardiac work. The model of the syngeneic heterotopically transplanted heart is conducive to separating these two possibilities. Cardiac transplantation into the abdominal cavity as previously described (12), allows for the maintenance of a vascularly perfused, spontaneously beating, essentially nonworking heart exposed to the same hormonal mileau as the in situ heart. Transplanted hearts of this type can be maintained with spontaneous rates of con- 
traction in a viable state for extended periods of time $(12,19)$. We postulated that if $\mathrm{T}_{4}$ directly effects the quantity of myocardial protein synthesis then the transplanted heart should hypertrophy like the in situ heart in experimental hyperthyroidism. If, in contrast, $T_{4}$ stimulates heart growth through changes in cardiovascular hemodynamics, then the in situ, but not the transplanted, heart should be so affected.

The results of the present studies clearly show that, as in previous reports, thyroid hormone causes a marked increase in the heart weight and protein content of the in situ working heart (5). In contrast, thyroid hormone treatment did not increase the heart weight, left ventricular weight, total heart protein, or left ventricular protein in the heterotopically transplanted nonworking heart. Measurements of protein synthesis were unaltered by thyroid hormone treatment at doses sufficient to increase both serum levels of $T_{4}$ and $T_{3}$. These results strongly support the concept that thyroxine-induced cardiac hypertrophy is mediated by changes in cardiac output and cardiac work. This data is similar to that obtained in myocyte cell culture (17), in vivo in rats treated simultaneously with $\mathrm{T}_{4}$ and propranolol (Klein, I., manuscript submitted for publication), and in cats with differential cardiac muscle loading (20), and supports the concept that cardiac work per se is an important mediator of myocardial protein synthesis $(6,7,17)$.

In the heterotopic heart removed from control euthyroid rats we have demonstrated a shift in myosin isoenzyme distribution and a simultaneous decrease in the specific activity of myosin ATPase. This observation is an additional confirmation of a myosin isoenzyme shift that occurs independently of changes in serum levels of thyroid hormone (16). The ability of excess thyroid hormone to reestablish the $V_{1}$ myosin isoenzyme distribution to levels observed in control adult hearts suggests a direct role for thyroid hormone, perhaps through the direct regulation of gene transcription $(21,22)$. Alternatively, since the heart rate in the thyroid hormone-treated heterotopic heart was significantly greater than that in control animals, a role of heart rate in the regulation of myosin isoenzyme distribution cannot be excluded.

The heterotopically transplanted heart is a denervated organ. Prior studies have suggested that the cardiac hypertrophic response to an increased workload occurs unaltered after denervation, alpha adrenergic, or beta adrenergic blockade $(20,23)$. A report that alpha adrenergic activity mediated the development of cardiac hypertrophy did not exclude the possibility that the trophic stimulus was alterations in contraction per se (24). However, in the present study it was impossible to exclude a permissive effect of cardiac innervation or adrenergic stimulation for the expression of thyroxine-induced muscle growth.

Although the present study suggests that the cardiac hypertrophic response to thyroid hormone is indirectly mediated, two potentially direct effects of $T_{4}$ on the heart were observed. First, the heart rate of $\mathrm{T}_{4}$-treated hearts (in situ and heterotopic) were faster than the respective control rates. We have observed that propranolol treatment blocked this increase in the in situ heart rate (Klein, I., manuscript submitted for publication). This suggests that increased adrenergic stimulation or, alternatively, a $\mathrm{T}_{4}$-mediated increase in beta adrenergic receptor number may explain these findings (25). Second, as noted above, it appears that excess $T_{4}$ reestablishes the myosin isoenzyme distribution in the heterotopic heart to a $95 \% \mathrm{~V}_{1}$. Thus, while $\mathrm{T}_{4}$-mediated hemodynamic changes appear to alter the synthetic rate of car- diac myosin indirectly through changes in protein synthesis, $T_{4}$ may qualitatively alter the transcription of the myosin message $(21,22)$. Direct analysis of the content and species of the mRNA for myosin in the transplanted and in situ myocardium would confirm this possibility.

The data in the present study support an important role for altered cardiac work as a mediator of thyroxine-induced cardiac hypertrophy. The current experiments do not resolve the question of whether thyroid hormone can directly alter cardiac contractility through any of a number of postulated mechanisms $(3,11,26)$. As with other forms of work-induced cardiac growth, the cellular mechanism responsible for linking these two processes is yet to be established.

\section{Acknowledgment}

The authors thank Ms. Monica Daood for her expert technical assistance and Ms. Yvonne F. Jones for preparation of the manuscript. Dr. T. R. Zerbe performed the pathological studies.

Dr. Klein is a Clinical Investigator of the Veterans Administration. This work was supported in part by National Institutes of Health grant 5T32 HL07557.

\section{References}

1. Klein, I., and G. S. Levey. 1984. New perspectives on thyroid hormone, catecholamines, and the heart. Am. J. Med. 76:167-172.

2. Grossman, W., N. L. Rubin, and L. W. Johnson. 1971. The enhanced myocardial contractility of thyrotoxicosis. Ann. Intern. Med. 74: 869-874.

3. Morkin, E., I. L. Flink, and S. Goldman. 1983. Biochemical and physiologic effects of thyroid hormone on cardiac performance. Prog. Cardiovasc. Dis. 25:435-464.

4. Daniel, S., H. L. C. Balvin, N. Lautensack-Belser, and H. E. Morgan. 1985. Faster protein and ribosome synthesis in thyroxine-induced hypertrophy of rat heart. Am. J. Physiol. 248:C309-C319.

5. Sanford, C. F., E. E. Griffin, and K. Wildenthal. 1978. Synthesis and degradation of myocardial protein during the development and regression of thyroxine-induced cardiac hypertrophy in rats. Circ. Res. 43:688-694.

6. Schreiber, S. S., C. D. Evans, M. Oratz, and M. A. Rothschild. 1981. Protein synthesis and degradation in cardiac stress. Circ. Res. 48: 601-611.

7. Coffelt, J. W., W. W. Parmley, and D. T. Mason. 1979. The cardiac hypertrophy process: analyses of factors determining pathological vs. physiological development. Circ. Res. 45:697-707.

8. Tsai, J. S., and H. H. Samuels. 1976. Thyroid hormone action: stimulation of growth hormone and inhibition of prolactin secretion in cultured GH cells. Biochem. Biophys. Res. Commun. 59:420-428.

9. Philipson, K. D., and I. S. Edelman. 1977. Thyroid hormone control of NaK-ATPase and K-dependent phosphatase in rat heart. Am. J. Physiol. 232:C196-C201.

10. Crie, J. S., J. R. Wakeland, B. A. Mayhew, and K. Wildenthal. 1983. Direct anabolic effects of thyroid hormone on isolated mouse heart. Am. J. Physiol. 245:C328-C333.

11. Kim, D., and T. W. Smith. 1985. Effects of thyroid hormone on calcium handling in cultured chick ventricular cells. J. Physiol. 364: 131-149.

12. Ono, K., and E. S. Lindsey. 1969. Improved technique of heart transplantation in rats. J. Thorac. Cardiovasc. Surg. 57:225-232.

13. McDermott, P., M. Daood, and I. Klein. 1985. Measurement of myosin ATPase and myosin content in cultured heart cells. Arch. Biochem. Biophys. 290:312-318. 
14. Lowry, O. H., N. J. Rosebrough, A. L. Farr, and R. J. Randall. 1951. Protein measurement with the Folin phenol reagent. J. Biol. Chem. 193:265-275.

15. Hoh, F. Y., P. A. McGrath, and P. T. Hale. 1978. Electrophoretic analysis of multiple forms of rat cardiac myosin: effects of hypophysectomy and thyroxine replacement. J. Mol. Cell. Cardiol. 10:1053-1076.

16. Dillmann, W. 1980. Diabetes mellitus induces changes in cardiac myosin of the rat. Diabetes. 29:579-582.

17. McDermott, P., M. Daood, and I. Klein. 1985. Contraction regulates myosin synthesis and myosin ATPase in cultured heart cells. Am. J. Physiol. 249:H763-769.

18. Milton, J., and J. O. Tsokos. 1983. Statistical Methods in the Biologic and Health Sciences. McGraw Hill, New York. 1-500.

19. Guttmann, R. D. 1974. Genetics of acute rejection of rat cardiac allografts and a model of hyperacute rejection. Transplantation (Baltimore). 17:383-389.

20. Cooper, G. IV, R. L. Kent, C. E. Uboh, E. W. Thompson, and T. A. Marino. 1985. Hemodynamic versus adrenergic control of cat right ventricular hypertrophy. J. Clin. Invest. 75:1403-1414.

21. Dillmann, W. A., A. Barrieaux, W. E. Neeley, and P. Contraras.
1983. Influence of thyroid hormone on the in vitro translational activity of specific mRNA's in the rat heart. J. Biol. Chem. 258:7738-7745.

22. Everett, A. W., W. A. Clark, R. A. Chizzonite, and R. Zak. 1983. Change in synthesis rates of $\alpha$ - and $\beta$-myosin heavy chains in rabbit heart after treatment with thyroid hormone. J. Biol. Chem. 258:24212422.

23. Sen, S., and R. C. Tarazi. 1983. Regression of myocardial hypertrophy and influence of adrenergic system. Am. J. Physiol. 244:H97H101.

24. Simpson, P. 1985. Stimulation of hypertrophy of cultured neonatal rat heart cells through an $\alpha_{1}$-adrenergic receptor and induction of beating through an $\alpha_{1}$-and $\beta_{1}$-adrenergic receptor interaction. Evidence for independent regulation of growth and beating. Circ. Res. 5b:884894.

25. Williams, L. T., R. J. Lefkowitz, and A. M. Watanabe. 1977. Thyroid hormone regulation of $\beta$-adrenergic number. J. Biol. Chem. 252:2787-2789.

26. Alpert, N. R., L. A. Mulieri, and R. Z. Litten. 1979. Functional significance of altered myosin adenosine triphosphatase activity in enlarged hearts. Am. J. Cardiol. 44:947-953. 